\title{
Novel Behavioral Tasks for Studying Spatial Cognition in Rats
}

\author{
D. KLEMENT, K. BLAHNA, T. NEKOVÁŘOVÁ \\ Institute of Physiology, Academy of Sciences of the Czech Republic, v.v.i, Prague, Czech Republic
}

Received February 15, 2008

Accepted April 16, 2008

On-line May 13, 2008

\begin{abstract}
Summary
Spatial tasks in rodents are commonly used to study general mechanisms of cognition. We review two groups of novel spatial tasks for rodents and discuss how they can extend our understanding of mechanisms of spatial cognition. The first group represents spatial tasks in which the subject does not locomote. Locomotion influences neural activity in brain structures important for spatial cognition. The tasks belonging to the first group make it possible to study cognitive processes without the interfering impact of locomotion. The second group represents tasks in which the subject approaches or avoids a moving object. Despite this topic is intensively studied in various animal species, little attention has been paid to it in rodents. Both groups of the tasks are powerful tools for addressing novel questions about rodent cognition.
\end{abstract}

\section{Key words}

Spatial cognition • Rats • Moving objects • Behavioral tasks

\section{Corresponding author}

D. Klement, Institute of Physiology, Academy of Sciences of the Czech Republic, Vídeňská 1083, 14220 Prague 4, Czech Republic. Fax: $\quad+420-241 \quad 062488$ E-mail: dklement@biomed.cas.cz

\section{Introduction}

Cognition and its neural substrate are intensively studied in many laboratories. Novel behavioral tasks with well characterized cognitive demands are necessary for further progress. Once a novel task is introduced, lesion, pharmacological or electrophysiological studies can be used to study whether and how certain brain areas are involved in the underlying cognitive processes. In rodents the research of learning and memory is focused on spatial cognition. Here we present two types of novel spatial tasks for rats: 1) tasks in which spatial cognition is tested in non-locomoting animals and 2) tasks in which the subjects navigate to or avoid a moving object. We discuss how these tasks contributed or can contribute to the research of spatial cognition.

\section{Non-locomotor spatial tasks}

Our knowledge of spatial cognition in rats is mainly based on observation of locomotion. Through the locomotion we study whether the subject is able to use available sensory stimuli for navigation or whether it remembers the location of a goal or of visited places. Nevertheless, some questions concerning spatial cognition are difficult to address by means of locomotor tasks. Below we show two examples: the importance of hippocampus for the ability to recognize places and the relationship between hippocampal theta rhythm and spatial cognition. To answer these and other questions it is important to use spatial tasks in which the locomotion is absent or at least minimized. Such tasks have used nonspatial operant behavior controlled by spatial stimuli (Klement and Bureš 2000, Paštálková et al. 2003, Kelemen et al. 2005, Nekovářová and Klement 2006, Klement et al. 2008). Typically an animal is trained to press a lever for reward but its responses are reinforced only when they occur in the presence of a to-berecognized spatial stimulus. Preferential responding in the presence of this stimulus indicates that the animal recognizes it.

Spatial tasks exploiting non-spatial operant behavior have been used to study the ability to recognize places (Klement and Bureš 2000, Paštálková et al. 2003) 
and the role of hippocampus in this ability (Klement et al. 2005). Hippocampus is necessary for navigation toward a place which can be found only according to its spatial relationship to distal landmarks (Morris et al. 1982). During such navigation the subject has to determine where to go in order to reach the place and, after it reaches the desired position, to recognize it. For example, rats easily learn to navigate toward a platform hidden under the water surface using distal cues present around the pool. If the platform is removed then they start to search for it in the location, where it was in the previous trials. The switch in behavior from goal directed navigation to random search indicates that the animals have recognized the place.

Researchers were interested whether the ability to recognize places depends on hippocampus. This question was addressed indirectly using spatial tasks in which rats should actively move to the location recognized as the goal place (Whishaw et al. 1995, Whishaw and Jarrard, 1996, Dudchenko et al. 2000, Pouzet et al. 2002, Hollup et al. 2001). These experiments provided contradictory results about the role of the hippocampus for place recognition. To help to resolve this question Klement and Bureš (2000) used non-spatial operant behavior controlled by spatial stimuli. They tested place recognition without asking the animal to actively move to the to-be-recognized place. Thus they isolated the place recognition process from the recall of the target position and from the navigation toward it. Food deprived rats were placed in the box located on the edge of a rotating arena and passively transported along a circular trajectory. They could press a lever all the time but their responses were rewarded by delivering a food pellet only if they occurred within a limited region in the experimental room. Accumulation of responses inside and in the vicinity of the region indicated that the rats were recognizing the region. Subsequent study showed that this task is hippocampal dependent (Klement et al. 2005). The result supported the view that hippocampus is necessary for recognizing places.

Several experiments demonstrated that theta rhythm is present in hippocampus when the animal moves across an environment or prepares for the movement (Vanderwolf 1969, Ranck 1973). Theta rhythm also organizes firing of hippocampal pyramidal cells (O'Keefe and Recce 1993) and it is involved in synaptic plasticity (Orr et al. 2001), phenomena thought to be associated with cognition. However, it was unclear whether theta rhythm reflects only locomotion or whether it is also triggered by cognitive processes taking place in hippocampus. To test this hypothesis it was necessary to use a hippocampal dependent task in which rats do not move. Kelemen et al. (2005) modified the place recognition task described by Klement and Bureš (2000). Rats were trained to hold their head motionless in a drinking device while they were passively transported along a circular trajectory. Licking was rewarded either in the to-be-recognized region or randomly. The frequency and the amplitude of theta rhythm were lower during the passive transport compared to the active locomotion. Nevertheless, there was no difference between theta rhythm during the hippocampal dependent place recognition task and during the random licking. Thus the result supported the hypothesis that theta rhythm primarily reflects locomotion.

Spatial cognition can be studied also in rats which do not change their location in an experimental room at all (Paštálková et al. 2003, Nekovářová and Klement 2006, Klement et al. 2008). Such experiments allow to study spatial cognition and neuronal activity reflecting the cognitive task in the absence of inertial stimuli which are inevitably present during active movement as well as during passive transport. Inertial stimuli influence hippocampal theta rhythm (Gavrilov et al. 1996), activity of place cells (Terrazas et al. 2005) and head-direction cells (Blair and Sharp 1996). Paštálková et al. (2003) used an operant chamber with a window through which the subject could observe a rotating scene. The rats were trained to recognize a particular displacement of the scene. The performance was equal to the performance observed in the same rats when they were passively transported around a stationary scene. In the following studies (Nekovářová and Klement 2006, Klement et al. 2008) rats were trained to press a lever when a light cursor moving across a computer screen was at the to-be-recognized place. These tasks make it possible to study representation of position and velocity of a moving object in the rat's brain.

It has been demonstrated that animals preferentially explore objects which changed their location between two consecutive sessions in comparison with objects remaining on the same place (Ennaceur et al. 1997). This preference is hippocampal dependent (Mumby 2002). O'Keefe and Nadel (1978) recorded hippocampal neurons that fired extensively when the animal did not find an object on a place where it was present in the previous sessions. Rivard et al. (2004) described hippocampal neurons with activity dependent 
on the presence of a particular object. The data indicate that animals chart stationary objects into their representation of an environment. However, moving objects cannot be simply charted into a spatial representation of the environment as they are not bound to any location. It remains an unsolved question whether there exist neurons representing position of these moving objects and whether they are located in hippocampus. Spatial task in which subjects are forced to observe a moving object can help to answer this question. The operant conditioning tasks presented in Nekovářová and Klement (2006) and Klement et al. (2008) are suitable for this purpose.

\section{Spatial tasks in which the subject responds to a moving object}

The second group of behavioral tasks concerns freely moving animal and its relation to objects moving in the environment.

In their natural habitats animals react to moving objects, e.g. to members of the same social group, mates, preys or predators. In order to reach or to avoid them the subject has to pay attention to them and quickly respond to their movements. Strategies evolved for catching a moving object was studied in different species (insect: Collet and Land 1978, Rossel 1980, fish: Rossel et al. 2002, Wohl and Schuster 2006, humans: McBeath et al. 1995). However there is a lack of corresponding tasks for rodents. Recently, novel tasks for rodents have been introduced. The animals were trained either to avoid a moving object (Paštálková and Bureš 2001, Svoboda et al. 2005, Blahna et al. 2007) or to approach it (Klement and Blahna 2007).

Paštálková and Bureš (2001), see also Fenton and Bureš (2003), developed a behavioral task in which one rat (prey) should avoid another rat (predator). Both rats were placed on a circular arena. If the distance between the predator and the prey was shorter than a preset critical distance then the prey received an aversive stimulus. Thus the prey should continuously monitor the distance to the predator and to increase it when it became necessary. Two factors made this task difficult: limited space of the arena and the tendency of the predator to make a social contact with the prey. To avoid these constraints Svoboda et al. (2005) replaced the predator rat by a mobile robot. The robot did not chase the rat and moved slower than the predator rat in the previous experiment. Rats increased the average distance to the robot as the result of training and thus decreased the number of received aversive stimuli. The increase distance can be partly explained by the increased time the rats spent at the arena wall (Telenský et al. 2006). Inactivation of the hippocampus by tetrodotoxin impaired rat's performance without changing the thigmotactic behavior and thus making it possible to interpret the result as a cognitive deficit (Svoboda et al. 2006). Since hippocampal rats are able to estimate distance from a single visible cue (Pearce et al. 1998), the result suggests that the observed impairment affected the ability to initiate an escape reaction at the right moment rather than the perception of distance. The avoidance task become much more difficult when rats were trained to keep safe distance from an object moving outside of the arena. Only minority of the animals learned the task and their asymptotic performance varied substantially between consecutive sessions (Blahna et al. 2007).

In all the above tasks the animals avoided moving objects on a dry arena. In contrast, Klement and Blahna (2007) designed a task in which rats should navigate to a platform moving along the wall in a circular water pool. The platform did not change its speed within the trials to makes it possible to predict its movement. Since the rats were not allowed to wait for the target at the wall they were forced to navigate toward the platform across the pool. When the platform moved slower than the rats, the animals most frequently swam directly toward the platform. When the platform moved faster than the rats, they swam at a point in front of the platform generating relatively straight trajectories toward the place of collision. Further experiments revealing the role of various brain structures such as hippocampus and prefrontal cortex in this task have to be carried on.

\section{Conclusions}

We presented two groups of novel behavioral tasks. The tasks in the first group are operant conditioning tasks. Their advantage is minimization or even elimination of locomotion in spatial tasks. It allows to study the role and the activity of different brain structures in non-locomoting animals while they process spatial information. The operant conditioning in spatial research allows applying sensory stimuli with high flexibility, particularly if they are displayed on a computer screen. The computer screen makes it possible to use almost countless number of different stimuli and their combinations as well as to precisely control latency 
and duration of stimuli presentation. In addition such behavioral tasks can be easily modified and they are suitable for comparing cognitive functions and their neuronal substrate in various animal species including humans. It is possible to design several versions of the task presented in Nekovářová and Klement (2006) in which all the experimental parameters such as timing, behavioral response, motivation are identical except the stimuli presented on the screen. In the same apparatus rats can be trained to recognize various patterns, configurations of stimuli or places. This phenomena is illustrated by increasing number of novel behavioral tasks using computer screen for presenting stimuli (Bussey et al. 2001, Keller et al. 2000, Nekovářová and Bureš 2006, Nekovářová et al. 2006, Prusky et al. 2004, Sahgal and
Steckler 1994).

The tasks in the second group address the cognitive and neural processes involved during navigation toward or away from moving objects. Despite this topic is intensively studied in various animal species, little attention has been paid to it in rodents. The novel behavioral tasks presented above will hopefully initiate this research in rodents.

\section{Conflict of Interest}

There is no conflict of interest.

\section{Acknowledgements}

The research was supported by grants AV0Z50110509 and Center for Neuroscience LC554.

\section{References}

BLAHNA K, OSECKÁ B, KLEMENT D: Representation of moving object in different character of environment. In: Neural Plasticity (39th Annual European Brain and Behaviour Society Abstracts), A TREVES, PP BATTAGLINI, L CHELAZZI, M DIAMOND, G VALLORTIGARA (eds), Hindawi Publishing Corporation, Trieste, 2007, pp 40-41.

BLAIR HT, SHARP PR: Visual and vestibular influences on head-direction cells in the anterior thalamus of the rat. Behav Neurosci 4: 643-660, 1996.

COLLET TS, LAND MF: How hoverflies compute interception courses. J Comp Physiol 125: 191-204, 1978.

DUDCHENKO PA, WOOD ER, EICHENBAUM H: Neurotoxic hippocampal lesions have no effect on odor span and little effect on odor recognition memory but produce significant impairments on spatial span, recognition, and alternation. J Neurosci 20: 2964-2977, 2000.

ENNACEUR A, NEAVE N, AGGLETON JP: Spontaneous object recognition and object location memory in rats, the effects of lesions in the cingulate cortices, the medial prefrontal cortex, the cingulum bundle and the fornix, Experimental Brain Research 113: 509-519, 1997.

FENTON AA, BUREŠ J: Navigation in the moving world. In: The Neurobiology of Spatial Behaviour. KJ JEFFERY (ed), Oxford University Press, Oxford, 2003, pp 240-258.

GAVRILOV VV, WIENER SI, BERTHOZ A: Whole-body rotations enhance hippocampal theta rhythmic slow activity in awake rats passively transported on a mobile robot. Ann N Y Acad Sci 781: 385-98, 1996.

HOLLUP SA, KJELSTRUP KG, HOFF J, MOSER MB, MOSER EI: Impaired recognition of the goal location during spatial navigation in rats with hippocampal lesions. J Neurosci 21: 4505-4513, 2001.

KELEMEN E, MORON I, FENTON AA: Is the hippocampal theta rhythm related to cognition in a non-locomotor place recognition task? Hippocampus 15: 472-479, 2005.

KLEMENT D, BLAHNA K: Rat navigation to a visible moving goal in Morris water maze. In: 39th Annual European Brain and Behaviour Society Abstracts. A TREVES, PP BATTAGLINI, L CHELAZZI, M DIAMOND, G VALLORTIGARA (eds), Neural Plasticity, 2007, p 40.

KLEMENT D, BUREŠ J: Place recognition monitored by location driven operant responding during passive transport of the rat over a circular trajectory. Proc Natl Acad Sci USA 97: 2946-2951, 2000.

KLEMENT D, PAŠŤÁLKOVÁ E, FENTON AA: Tetrodotoxin infusions into the dorsal hippocampus block nonlocomotor place recognition. Hippocampus 15: 460-471, 2005.

MCBEATH MK, SHAFFER DM, KAISER MK: How baseball outfielders determine where to run to catch fly balls. Science 268: 569-573, 1995. 
MORRIS RG, GARRUD P, RAWLINS JN, O'KEEFE J: Place navigation impaired in rats with hippocampal lesions. Nature 297: 681-683, 1982.

MUMBY DG, GASKIN S, GLENN MJ, SCHRAMEK TE, LEHMANN H: Hippocampal damage and exploratory preferences in rats: memory for objects, places and contexts. Learn Mem 9: 49-57, 2002.

NEKOVÁŘOVÁ T, KLEMENT D: Rat's operant behavior can be controlled by the configuration of objects in an animated scene displayed on a computer screen. Physiol Res 55: 105-113, 2006.

NEKOVÁŘOVÁ T, BUREŠ J: Spatial decisions in rats based on the geometry of computer-generated patterns. Neurosci Letters 394: 211-215, 2006.

NEKOVÁŘOVÁ T, NEDVÍDEK J, BUREŠ J: Spatial choices of rats based on abstract visual information: pattern- or configuration-discrimination? Behav Brain Res 172: 264-271, 2006.

O'KEEFE J, RECCE ML: Phase relationship between hippocampal place units and the EEG theta rhythm. Hippocampus 3: 317-330; 1993.

O'KEEFE J, NADEL L: The Hippocampus as a Cognitive Map. Clarendom Press, Oxford, 1978.

ORR G, RAO G, HOUSTON FP, MCNAUGHTON BL, BARNES CA: Hippocampal synaptic plasticity is modulated by theta rhythm in the fascia dentate of adult and aged freely behaving rats. Hippocampus 6: 647-654, 2001.

PAŠŤÁLKOVÁ E, BUREŠ J: How do animals navigate to avoid each other? Abstracts of the Fourth Conference of the Czech Neuroscience Society, Prague, 2001, p 104.

PAŠŤÁLKOVÁ E, KELEMEN E, BUREŠ J: Operant behavior can be triggered by the position of the rat relative to objects rotating on an inaccessible platform. Proc Natl Acad Sci USA 100: 2094-2099, 2003.

POUZET B, ZHANG WN, FELDON J, RAWLINS JN: Hippocampal lesioned rats are able to learn a spatial position using non-spatial strategies. Behav Brain Res 133: 279-291, 2002.

PRUSKY GT, DOUGLAS RM, NELSON L, SHABANPOOR A, SUTHERLAND RJ: Visual memory task for rats reveals an essential role for hippocampus and perirhinal cortex. Proc Natl Acad Sci USA 101: 5064-5068, 2004.

RANCK JB Jr.: Studies on single neurons in dorsal hippocampal formation and septum in unrestrained rats. I. Behavioral correlates and firing repertoires. Exp Neurol 41: 461-531, 1973.

RIVARD B, LI Y, LENCK-SANTINY PP, POUCET B, MULLER U: Representation of objects in space by two classes of hippocampal pyramidal cells. J Gen Physiol 124: 3-6, 2004.

ROSSEL S, CORLIA J, SCHUSTER S: Predicting three-dimensional target motion: How archer fish determine where to catch their dislodged prey $J$ Exp Biol 205: 3321-3326, 2002.

SAHGAL A, STECKLER T: Touch windows and operant behaviour in rats. $J$ Neurosci Methods 55: 59-64, 1994.

SVOBODA J, TELENSKÝ P, BLAHNA K, PAŠŤÁLKOVÁ E, BUREŠ J: Introducing of moving object into behavioral spatial tasks: moving object avoidance in rats. Homeostasis 43: 4, 2005.

SVOBODA J, TELENSKÝ P, BLAHNA K, BUREŠ J: Functional inactivation of dorsal hipocampus impairs spatial avoidance of moving object in rats. Abstracts of the Fifth Forum of European Neuroscience, Vienna, 2006, p 140.

TELENSKÝ P, JIROUTEK P, SVOBODA J, BLAHNA K, BUREŠ J: Biologická evoluce versus evoluční systémy: porovnání učení potkana a robota $\mathrm{v}$ dynamických prostorových úlohách srovnatelného typu. In: Kognice a umélý život VI. J KELEMEN, V KVASNIČKA (eds): Ediční středisko FPF SU, Opava, 2006, pp 373-391.

TERRAZAS A, KRAUSE M, LIPA P, GOTHARD KM, BARNES CA, MCNAUGHTON BL: Self-motion and the hippocampal spatial metric. J Neurosci 25, 8085-8096, 2005.

VANDERWOLF CH: Hippocampal electrical activity and voluntary movement of the rat. Electroencephalogr Clin Neurophysiol 26: 407-418, 1969.

WHISHAW IQ, CASSESL JC, JARRAD LE: Rats with fimbria-fornix lesions display a place response in a swimming pool: a dissociation between getting there and knowing where. J Neurosci 15: 5779-5788, 1995.

WHISHAW IQ, JARRAD LE: Evidence for extrahippocampal involvement in place learning and hippocampal involvement in path integration. Hippocampus 6: 513-524, 1996.

WOHL S, SCHUSTER S: Hunting archer fish match their take-off speed to distance from the future point of catch J Exp Biol 209: 141-151, 2006. 